\title{
ENSINO E PROJETO URBANO: UMA RESPOSTA AOS DESAFIOS CONTEMPORÂNEOS
}

\author{
ENSINO Y PROYECTO URBANO: UNA RESPOSTA A LOS DESAFIOS CONTEMPORANEOS
}

EDUCATION AND URBAN PROJECT: AN ANSWER TO CONTEMPORARY CHALENGES

\author{
ALBERNAZ, MARIA PAULA \\ Doutora em Geografia, PROURB/FAU/UFRJ, mpaula.albernaz@gmail.com
}

\section{RESUMO}

Este artigo visa contribuir para a reflexão acerca da relação entre o ensino de arquitetura e o projeto urbano, avaliando aspectos a serem considerados no contexto das metrópoles latino-americanas e as particularidades de um projeto voltado a melhoria da qualidade de vida urbana. Com este propósito analisa, por um lado, temáticas relacionadas à Metrópole do Rio de Janeiro; e, por outro, os fundamentos teóricos, metodologias e ferramentas pedagógicas, tendo como referência uma experiência de ensino de projeto urbano realizada no âmbito de disciplina da grade curricular do curso de graduação de arquitetura e urbanismo. Para exemplificar e analisar as questões apresentadas, utiliza produtos acadêmicos elaborados por equipes de alunos da disciplina que adotaram premissas diferenciadas e chegaram a resultados variados. Em complemento, também são apresentados premissas e resultados de projeto de pesquisa e extensão que servem de insumo permanente para alimentar a discussão pedagógica. A partir daí, avalia-se a necessidade, ao lidar com o projeto urbano, de se criar novas lógicas mais próximas das pessoas afetadas, associando-o a uma visão do cotidiano, que possibilite reconstruir ambientes urbanos coerentes com demandas da metrópole latino-americana contemporânea.

PALAVRAS-CHAVE: arquitetura e urbanismo; projeto urbano; ensino de arquitetura; acupuntura urbana; cidade do Rio de Janeiro.

\section{RESUMEN}

Este articulo tiene como objetivo contribuir en la reflexión acerca la relación entre lo enseno de arquitectura y lo proyecto urbano, evaluando aspectos a considerar en lo contexto de las metrópolis latino-americanas y las particularidades de uno proyecto volteado a la mejora de la cualidad de vida en la ciudad. Con este propósito se analiza por un lado, temáticas relacionadas a la Metrópoli do Rio de Janeiro; e por otro, los fundamentos teóricos, metodologías y herramientas pedagógicas tiendo como referencia la experiencia de enseno de proyecto urbano realizada en la disciplina de la grade curricular de lo curso de pregrado en arquitectura y urbanismo. Para ejemplificar y analizar las cuestiones presentadas utiliza algunos productos académicos elaborados por equipos de alumnos de la disciplina objeto de la experiencia que adoptaran premisas diferenciadas e llegaran a resultados variados. En complemento también son presentados los proyectos de investigación y extensión que se desarrollan en lo ámbito académico y sirven de insumo permanente para alimentar la discusión pedagógica. Evalúa-se la necesidad de criar nuevas lógicas más cercas de las personas afectadas, asociadas a una visión de lo cotidiano, que posibilite reconstruir los ambientes urbanos según las demandas y necesidades de la metrópoli latino-americana contemporánea.

PALABRAS CLAVES: arquitectura y urbanismo; proyecto urbano; ensino de arquitectura; acupuntura urbana; ciudad de Rio de Janeiro.

\section{ABSTRACT}

This article aims to reflect about the relationship between Architecture and Urbanism education and Urban Project, considering conceptual and pedagogical issues and the context of the Latin-American metropolis towards a better quality of life in the city. Therefore, we analyze in one side, problems related to the Metropolis of Rio de Janeiro; and the other, theoretical and methodological background and pedagogical tools from an experience in teaching Urban Project within one of the curricular subject of the Architecture and Urbanism undergraduate course. To analyze the presented questions we use as examples the academic products executed by groups of students from this curricular subject. They have adopted distinct premises and have arrived to different results. In complement we also present the research projects and the extension projects that have served as permanent inputs to the pedagogical discussion. In the end we evaluate the need to create new logics that are closer to people evolved, as well as a vision of the daily life, in order to reconstruct the urban environments according to demands and needs of the contemporary Latin-American metropolis.

KEYWORDS: architecture and urbanism; urban project; architecture teaching; urban acupuncture; city of Rio de Janeiro. 


\section{INTRODUÇÃO}

Neste início de milênio, o crescimento das grandes cidades e seu alcance pela maior parte da população nos países latino-americanos, se apresentam como um grande desafio. Nas duas maiores cidades metropolitanas brasileiras, São Paulo e Rio de Janeiro, hoje residem $20 \%$ da população urbana do Brasil. Problemas urbanos ligados à concentração da pobreza e à bastante desigual distribuição de renda que repercutem na enorme distinção dos locais de moradia, acrescidos da ausência de investimentos suficientes em infraestrutura e planejamento, demandam urgência e criatividade em seu enfrentamento (SANTOS, 1989). No atual debate em torno das grandes cidades, podemos destacar questões relacionadas ao acesso à moradia digna - de difícil resolução a curto ou mesmo médio prazo; aos fluxos e mobilidade, representando tempos insuportáveis de deslocamentos; ao patrimônio natural e cultural urbano, vulneráveis por uma ocupação irregular e carências no saneamento; à utilização dos espaços públicos, cada vez mais privatizados; e à dispersão geográfica urbana.

Por trás das estatísticas acerca do crescimento metropolitano e seus problemas, há diferentes realidades que interligam forma urbana e sociedade (BURDETT y RODE, 2007), tanto referentes às distintas cidades quanto aos distintos solos urbanos. A distribuição desigual dos meios de consumo coletivos, as dificuldades de acesso à terra urbana, a presença ou ausência de amenidades, a proximidade ou distância de instalações especiais são aspectos que geram evidentes diferenciações de valor no espaço urbano. Neste sentido se insere a relevância das escolhas para atuação através de um projeto urbano que pode valorizar ou desvalorizar o solo. Enfim, a problemática urbana contemporânea nos grandes centros brasileiros é complexa e não permite idealizar uma única solução, nem um modelo ou um programa que se reproduza. Torna-se necessário buscar critérios apoiados em lugares para definir intervenções, respeitando as sedimentações e as estratificações da história.

Este artigo pretende contribuir para a reflexão acerca da relação entre ensino de arquitetura e o projeto urbano, avaliando aspectos conceituais e pedagógicos a considerar no contexto das metrópoles latinoamericanas. Assim, por um lado, analisa temáticas relacionadas à Metrópole do Rio de Janeiro; e por outro, debruça-se em considerações acerca do campo de atuação do ensino da arquitetura e urbanismo referenciado ao projeto urbano. Para exemplificar e analisar as questões apresentadas, utiliza alguns produtos acadêmicos elaborados por equipes de alunos cursando disciplina da grade curricular de graduação em arquitetura e urbanismo na Faculdade de Arquitetura e Urbanismo da Universidade Federal do Rio de Janeiro que adotaram premissas diferenciadas e chegaram a resultados variados. Em complemento, também são apresentados encaminhamentos de projetos de pesquisa e extensão desenvolvidos igualmente no âmbito acadêmico que servem de insumo permanente para alimentar a discussão pedagógica.

Os projetos urbanos são entendidos como um mecanismo que responde às características e problemas variados da cidade contemporânea e que podem satisfazer em um período de tempo de curto a médio prazo as demandas expressas na sociedade (SECCHI, 2000, p. 91). Têm também a capacidade para articular as dimensões setoriais e espaciais, introduzindo requisitos que compreendem desde questões do desenvolvimento social e econômico às do desenho urbano e construção (TSIOMIS, 1996, p.24). Lidar com o projeto urbano exige um exame da noção de estratégia urbana - percebida como "a eleição do modo de conseguir chegar aos fins em um ambiente de incerteza” (PORTAS, 1996, p. 30). Não pode ser visto como um projeto de arquitetura em grande recorte territorial, mas como uma concepção complexa que não estará de todo definida e que poderá eventualmente absorver projetos futuros.

\section{METRÓPOLE DO RIO DE JANEIRO}

\section{Estrutura urbana e configuração espacial}

A Região Metropolitana do Rio de Janeiro inclui hoje 21 municípios: Belfort Roxo, Cachoeira de Macacu, Duque de Caxias, Guapimirim, Itaboraí, Itaguaí, Japeri, Magé, Maricá, Mesquita, Nilópolis, Niterói, Nova Iguaçu, Paracambi, Queimados, Rio Bonito, Rio de Janeiro, Seropédica, São Gonçalo, São João de Meriti e Tanguá. Com uma população estimada de 12,2 milhões de habitantes, ocupa uma área de 6,7 milhões de $\mathrm{km}^{2}$ na qual se encontram muitos maciços montanhosos, áreas de depressões e cursos d'água. Para além desses elementos geográficos, sua estrutura se configura a partir de eixos de transportes que conectam centros de maior ou menor alcance, como se verifica na Figura 1. 
Figura 1 - Estrutura da Região Metropolitana do Rio de Janeiro.

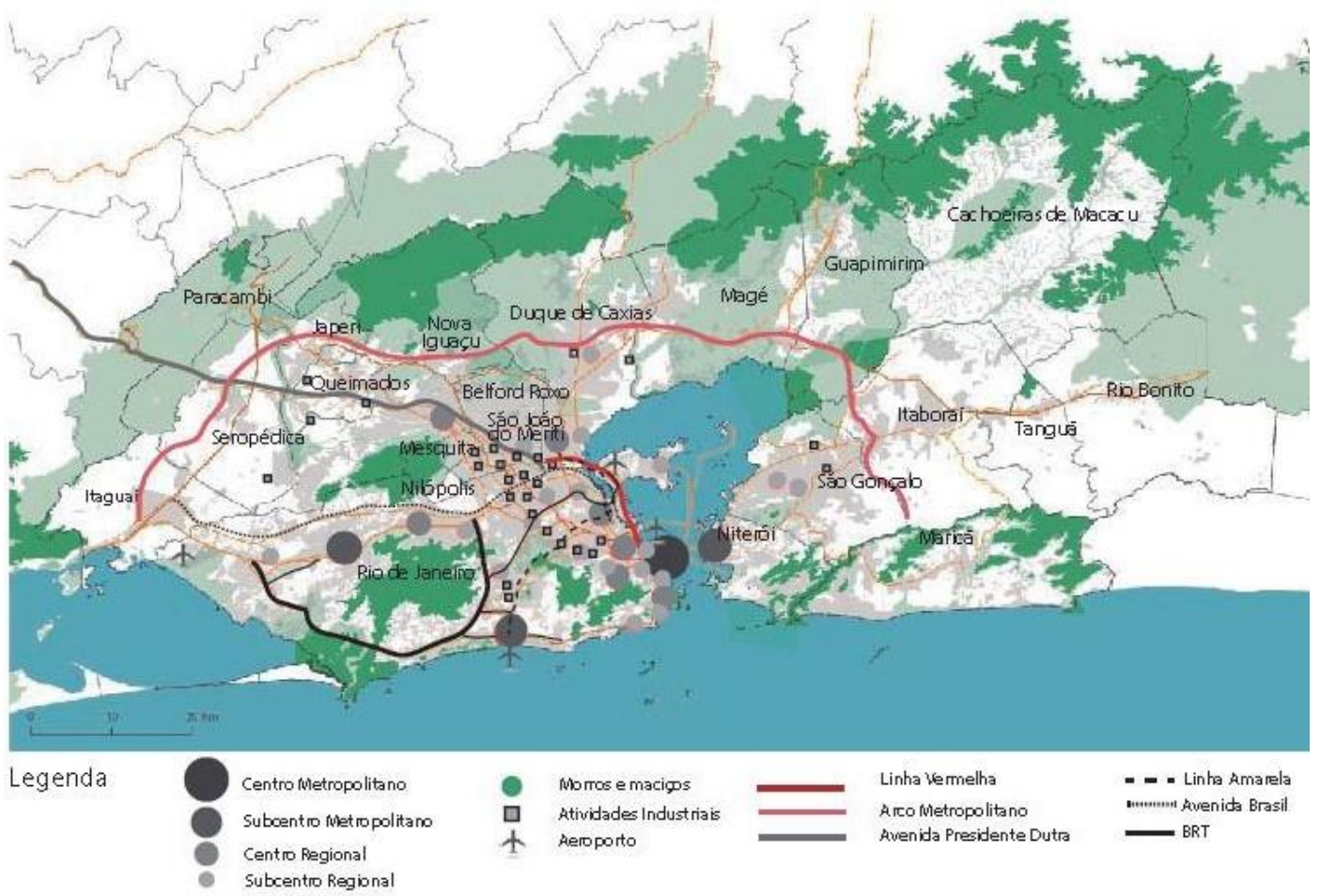

Fonte: Câmara Metropolitana de Integração Governamental. http://www.camarametropolitana.rj.gov.br (editado pela autora)

Historicamente, os municípios metropolitanos gradualmente vão constituindo uma mancha urbana quase contínua (ver Figura 2), configurando um modelo espacial monocêntrico a partir de seu núcleo, a cidade do Rio de Janeiro. Suas áreas periféricas desde sempre estabelecem fortes relações de dependência ao núcleo. O crescimento urbano dessa mancha ocorreu principalmente através de uma ocupação desordenada de áreas antes rurais que margeavam os eixos de transportes que conectavam a cidade do Rio de Janeiro às principais fontes de produção agrícola ou mineradora.

Figura 2 - Evolução da dinâmica demográfica metropolitana do Rio de Janeiro

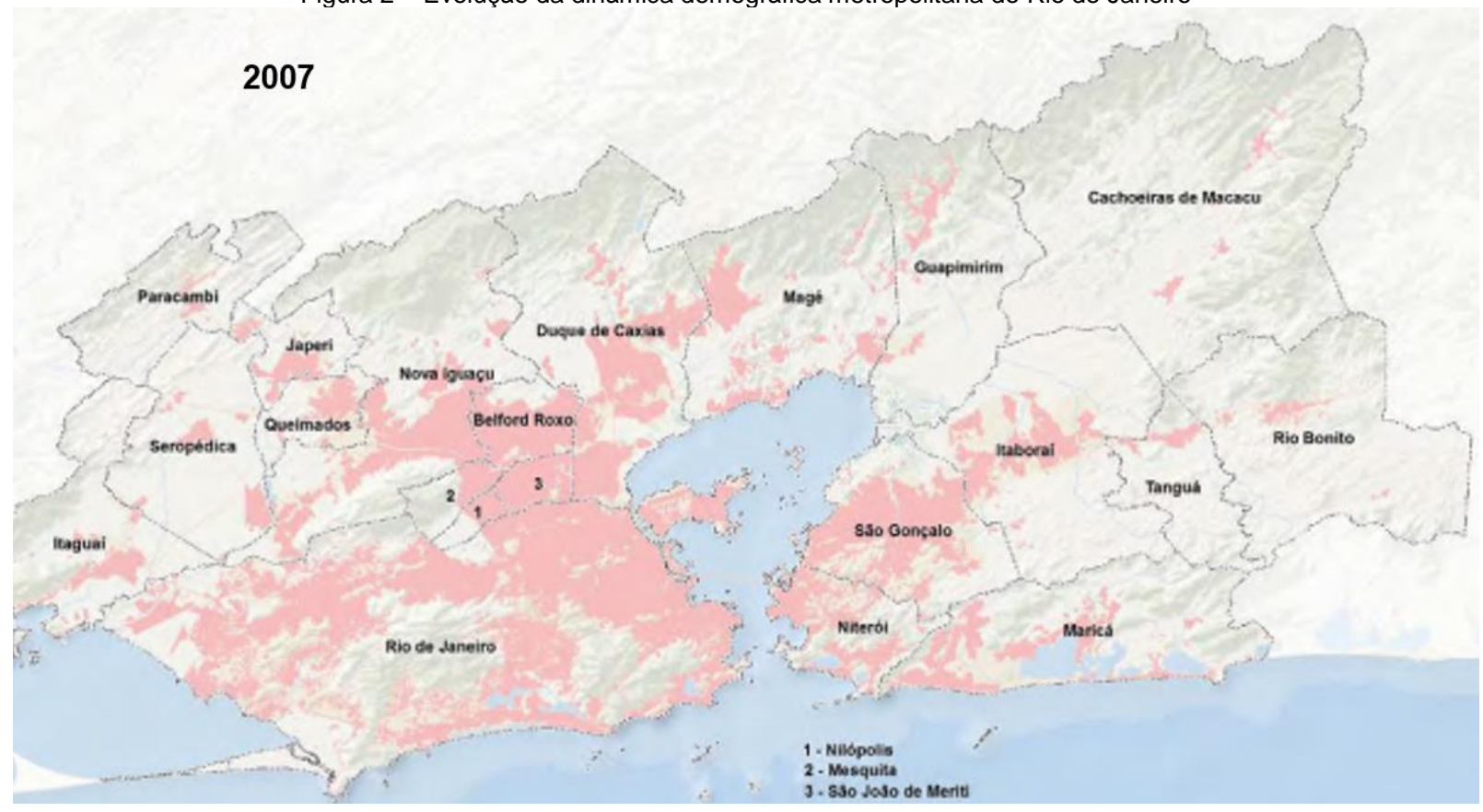




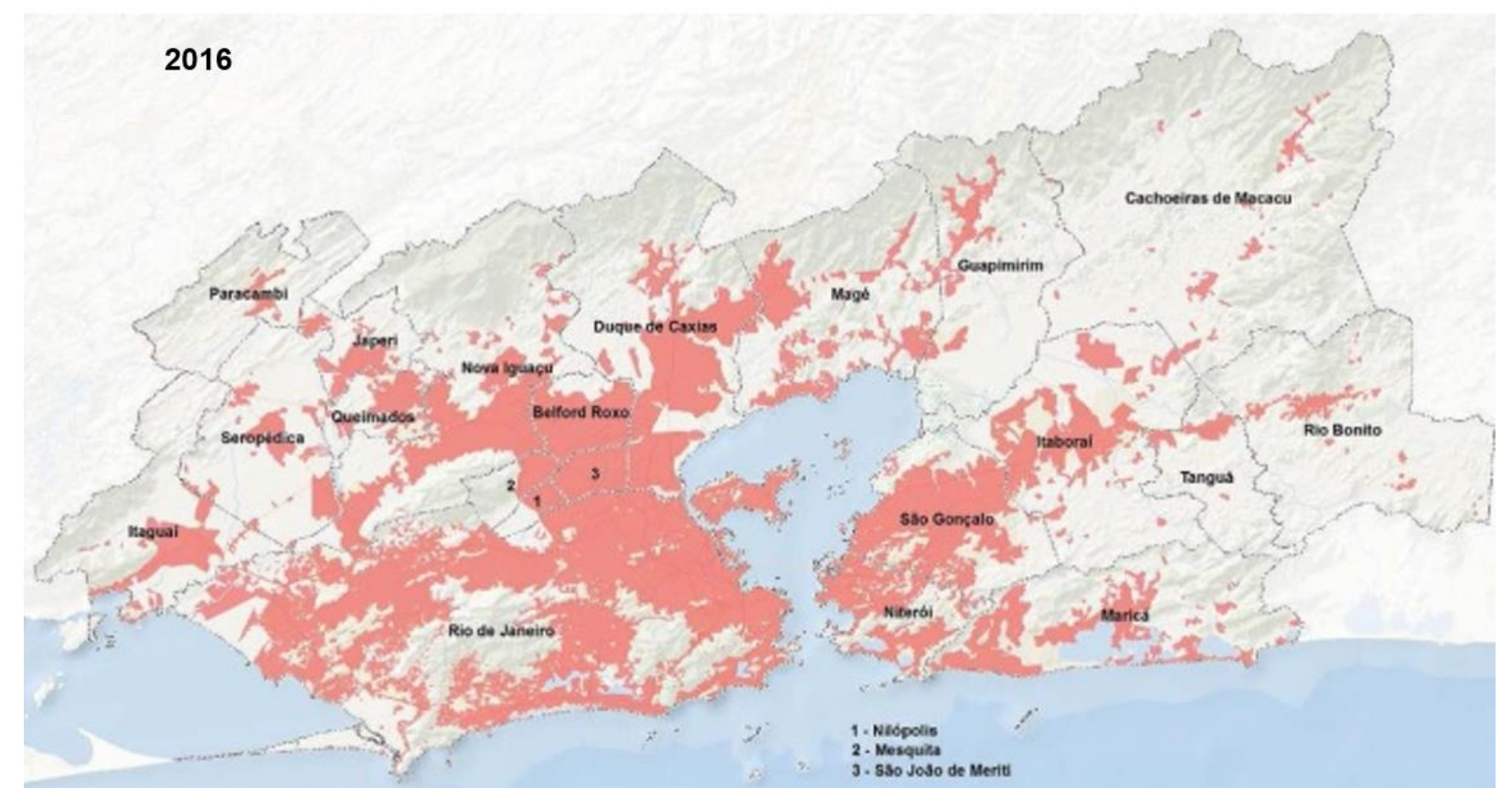

Fonte: Câmara Metropolitana de Integração Governamental. http://www.camarametropolitana.rj.gov.br (editado pela autora)

Frequentemente, na expansão metropolitana foi desconsiderada a adequação do solo ao uso urbano. A ocupação ocorreu tanto em terras inundáveis como nas encostas de morros. Também houve uma total despreocupação com a infraestrutura, os equipamentos e os serviços urbanos. Comumente o resultado até hoje observado diz respeito a uma urbanização precarizada que apresenta como principais características:

- Ausência de transição entre o rural e o urbano, mesmo se verificadas as duas formas de ocupação, com limites territoriais urbanos extremamente dinâmicos e difusos;

- Intensa fragmentação territorial, com crescente concentração e consolidação das aglomerações, e troca significativa nas espacialidades;

- Confluência de fluxos multidirecionais de pessoas, mercadorias e informações nos policentros constituídos por aglomerações concentradas;

- Redução relativa do crescimento demográfico no núcleo central com simultânea expansão territorial do ambiente construído que permeia espaços cada vez mais extensos e dispersos, com aumento da população metropolitana;

- Intensificação dos movimentos pendulares principalmente entre o núcleo central e os demais policentros metropolitanos, consagrando uma expressiva estrutura regional em rede.

O traço mais forte da configuração metropolitana é a distinção socioespacial do seu território, no que se refere à infraestrutura, aos equipamentos e serviços urbanos, além da oferta de emprego e trabalho e ao poder aquisitivo da população residente. O Rio de Janeiro, área central metropolitana, é o polo no qual se concentram equipamentos de educação, saúde e cultura, bem como atividades econômicas, que se tornam mais e mais escassos à medida que se afastam do núcleo. Entretanto, há uma quebra nessa estratificação centro-periferia causada pela presença de favelas que permeiam quase todo território metropolitano, repercutindo significativamente na estrutura de segregação socioespacial da Metrópole do Rio de Janeiro. Ela resulta em uma enorme diferenciação referente à distribuição das residências das camadas sociais e, consequentemente, das condições de vida no interior das macrorregiões urbanas. Somente no município do Rio de Janeiro cerca de um quarto de sua população reside em favelas. Um dos maiores conjuntos de favelas metropolitanas, o Complexo da Rocinha, com mais de 50 mil moradores, se localiza na Zona Sul, área mais valorizada da Metrópole.

Em relação à rede de centros e subcentros metropolitanos se observa que estes também estão concentrados no município do Rio de Janeiro, núcleo metropolitano. Este fato revela a monofuncionalidade residencial e a dependência à área central de grande parte das periferias metropolitanas. Verifica-se igualmente a insuficiência de centros e subcentros frente à extensão territorial da Metrópole. Ainda a destacar na Região Metropolitana do Rio de Janeiro a presença de áreas de vegetação natural em mais de $30 \%$ de seu território. Encontram-se, sobretudo, nas encostas dos maciços, onde frequentemente disputam espaços com as ocupações irregulares. Menos frequentes são os manguezais, e raras as restingas 
bordeando o mar. As áreas de ambiente natural legalmente protegidas correspondem a mais de $15 \%$ do território metropolitano.

\section{Desafios metropolitanos a enfrentar}

A falta de planejamento ao longo do tempo na Metrópole do Rio de Janeiro e a ausência de controle no processo de ocupação urbana resultaram em um quadro atual de problemas de diversas ordens. Uma das consequências desastrosas são as inundações e deslizamentos que ocorrem quando há grandes chuvas, comumente atingindo populações socialmente mais vulneráveis. As carências de infraestrutura, de equipamentos de saúde, educação e lazer, e de serviços urbanos também são um traço da precariedade. Destaca-se a urgente necessidade de qualificação de diferentes pontos do território metropolitano, respeitados os condicionantes físicos e ambientais.

Verifica-se um déficit habitacional de difícil resolução a curto ou médio prazo. O tempo gasto com deslocamento até o Centro metropolitano é outra dificuldade crucial para a maior parte das populações metropolitanas. Com base no modal rodoviário, desconsiderando quase sempre um sistema intermodal em rede, o transporte coletivo é muito deficiente, provocando má qualidade de vida urbana e ambiental. Mesmo com proteção legislativa, a maior parte dos ambientes naturais está em situação de vulnerabilidade, pela ocupação irregular ou carência de saneamento.

O descaso com o espaço público urbano, priorizado para o fluxo de veículos, associado a uma crescente fragmentação do tecido urbano por enclaves territoriais, agravam o recorrente e grave problema de insegurança. As consequências da dispersão urbana e da reduzida densidade são de pioria da segregação social, o empobrecimento e o desenraizamento de grupos da população.

Neste sentido, sobressaem duas frentes de ação, a primeira delas apontada pela recente implantada Câmara Metropolitana do Estado do Rio de Janeiro, para melhoria da qualidade da vida urbana e ambiental metropolitana a curto ou médio prazo: o reforço às centralidades já presentes no território da Metrópole e a ocupação de espaços subutilizados urbanos em áreas com melhor infraestrutura. Essas frentes buscam reduzir os esforços com os deslocamentos pendulares da moradia para o trabalho assim como para locais que possuem equipamentos e serviços através da criação de alternativas para o habitar e a concepção de formas de ocupação mais equilibradas socialmente e espacialmente.

\section{A REALIDADE METROPOLITANA NO ENSINO DE PROJETO URBANO}

\section{Ensino, pesquisa e extensão nos subúrbios cariocas}

Com a implementação de programas de apoio aos estudantes oriundos das camadas de baixa renda da população, hoje no Brasil vem se alterando mesmo que timidamente o perfil dos alunos dos cursos de nível superior, anteriormente à chegada do milênio, provenientes em sua grande maioria das elites econômicas. Atualmente há um número bem superior de estudantes nas faculdades de arquitetura e urbanismo que residem nas áreas suburbanas e periféricas da Metrópole do Rio de Janeiro. Esta condição favorece iniciativas destinadas a responder demandas metropolitanas contemporâneas.

A experiência relatada neste artigo apresenta fundamentos e metodologias pedagógicas, assim como resultados alcançados nos últimos cinco anos pelos seus alunos, em disciplina denominada Atelier Integrado II, turma B, na qual leciono em conjunto com mais três docentes, cuja proposta para estudantes cursando o $8^{\circ}$ período semestral letivo é desenvolver um projeto urbano em área consolidada da cidade do Rio de Janeiro. Nas reflexões ao longo do tempo acerca do alcance do trabalho, enfoque e produtos dos alunos, se identificam questões para o debate sobre o ensino do projeto urbano. Os resultados de investigações morfológicas e projeto de extensão que alimentam o trabalho pedagógico também servem de insumo para essas reflexões.

Há aproximadamente seis anos a ênfase na disciplina tem sido o projeto urbano para a Zona Norte do Rio de Janeiro - região de residência dos estratos médios e baixos da população, com razoável infraestrutura e oportunidades para o reforço e a qualificação de centralidades, densificação residencial e valorização da cultura local. Esta região se contrapõe à área central (Centro) e à Zona Sul da cidade, na qual os estratos mais ricos preferem viver, e é também identificada como subúrbios cariocas, apesar de não ser geograficamente periférica (Ver Figura 3). 
Figura 3 - Subúrbios Cariocas na Metrópole do Rio de Janeiro.

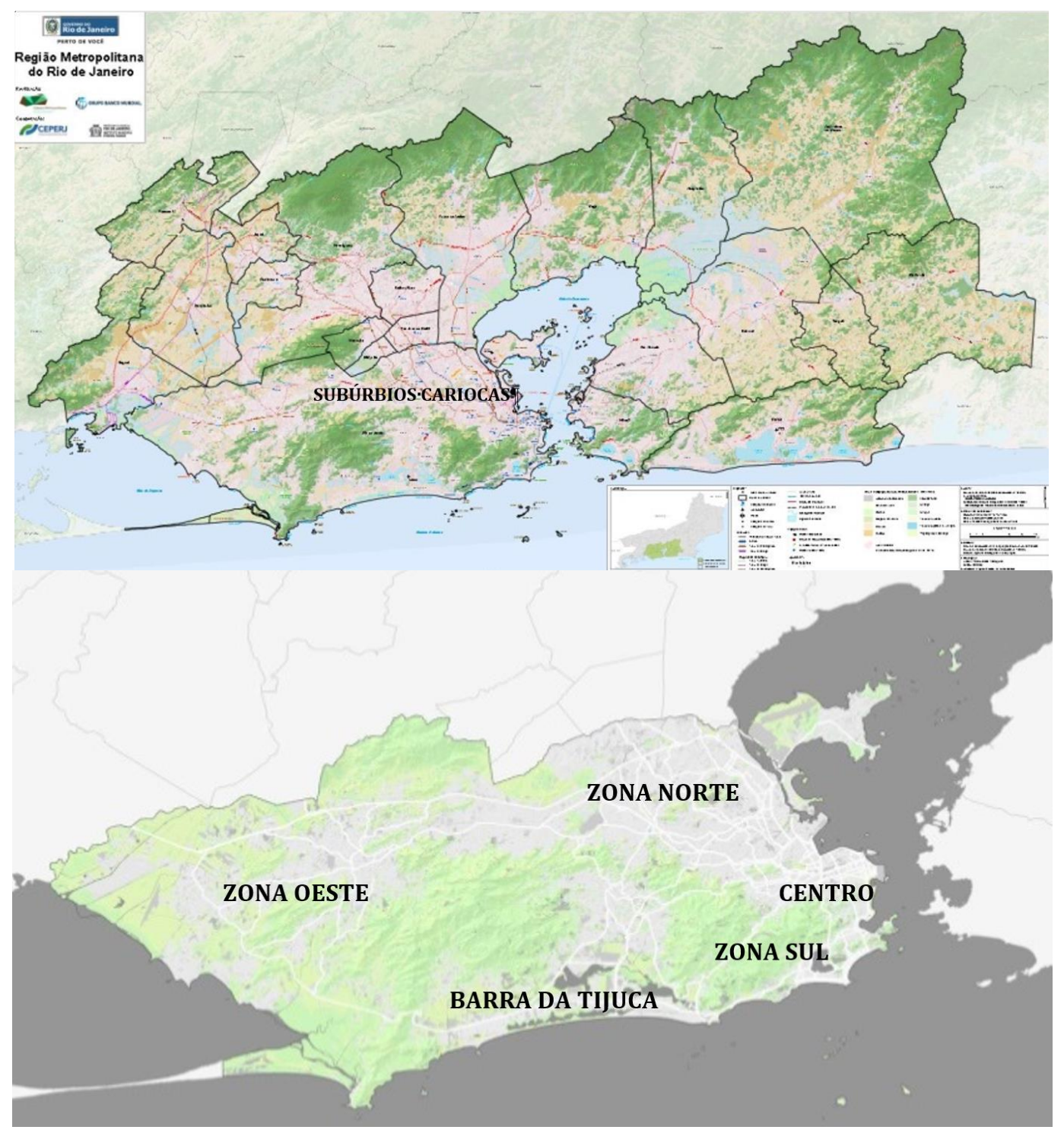

Fonte: http://www.camarametropolitana.ri.gov.br (editado pela autora)

Subúrbios cariocas é uma área relativamente próxima do Centro, com uma rede de transportes ferroviária, metroviária e de BRT. Os trens - elemento chave e comum na estruturação suburbana - cortaram seu território em momentos sequenciais induzidos por razões distintas (ABREU, 2006 [1987]), revelando-se por conta disso um motivador tanto de sua homogeneidade quanto de sua diferenciação interna. Desde os primeiros planos urbanos concebidos para então Capital Federal Rio de Janeiro na primeira metade do século XX, muitas áreas suburbanas se destinaram a implantação de estabelecimentos fabris (ABREU, op. cit.). O legado hoje desta destinação são amplos terrenos subutilizados e inúmeras favelas localizadas nas encostas dos morros e em terras inundáveis surgidas depois dos anos 1940, ocupadas por pessoas que buscavam oferta de trabalho fabril.

Inicialmente, o modal ferroviário foi implantado no Rio de Janeiro para transporte da produção agrícola, sendo inaugurado em 1858 para esse fim o hoje chamado Ramal Central-Deodoro. Na sequência, entre 1870 e 1990, nova linha do mesmo ramal, passando por terras próximas, voltou-se ao atendimento de passageiros - uma população de estrato médio que crescia na cidade e buscava transporte coletivo para acesso ao Centro polo gerador de trabalho. Logo em seguida, em 1886, em outra porção suburbana, foi atravessada pelas linhas férreas, sendo aberto o então chamado Ramal Rio d'Ouro (atualmente eixo da linha metroviária) para servir o recém-criado sistema de abastecimento de água. E ainda em outra porção, em 1893, se estabeleceu o Ramal da Leopoldina, visando abrir acesso para instalação de grandes estabelecimentos fabris em terras pouco ocupadas por serem inundáveis (ver Figura 4). 
Figura 4 - Linhas férreas nos subúrbios cariocas.

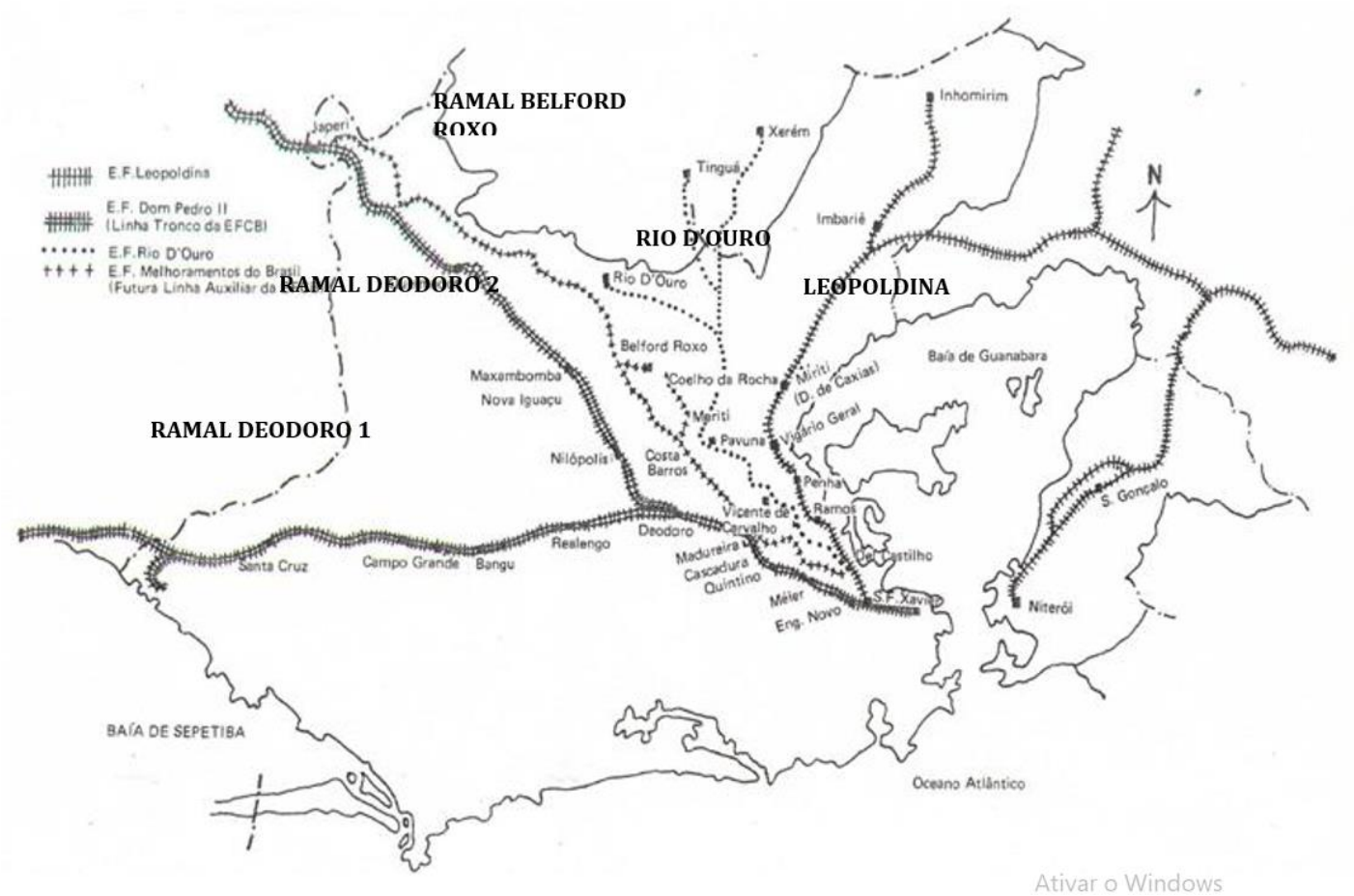

Fonte: ABREU (2006 [1987]) (editado pela autora)

A motivação para escolha da Zona Norte/subúrbios como área de projeto se remete às possibilidades de responder aos desafios metropolitanos assinalados acima, inclusive o combate à dispersão metropolitana, e também de aproveitar o potencial de interesse e conhecimento acerca da região por parte dos estudantes que residem nas áreas suburbanas ou a vivenciam. Ademais pesou na seleção o intuito de privilegiar uma região muito pouco contemplada por inversões públicas, pois no Rio, historicamente essas vêm sendo destinadas ao Centro e Zona Sul, sendo associadas aos interesses do capital ligado ao mercado fundiário e imobiliário.

A partir dessa opção, e com a busca por informações junto aos agentes locais, revelou-se igualmente o interesse em projeto de extensão e de pesquisa privilegiando os subúrbios cariocas. O objetivo no trabalho de extensão tem sido o de apoiar as ações dos movimentos envolvidos com a valorização e preservação da identidade suburbana que é entendida enquanto uma multiplicidade de expressões arquitetônicas e urbanísticas e manifestações culturais locais que compartilham de aspectos essenciais únicos. O propósito é de fortalecer sentimentos de pertencimento na população e consequente, cuidados com o território. No trabalho de pesquisa a intenção é de investigar trechos do tecido urbano em uma escala aproximada, através de uma abordagem morfológica, com o empenho em decifrá-las sob o ponto de vista das demandas da cidade contemporânea e a partir daí, entender que lições podem fornecer para a constituição de novos paradigmas de intervenção projetual.

Através dos avanços do projeto de extensão em termos de trocas de experiência com agentes locais, e das investigações da pesquisa no solo suburbano, que vêm ocorrendo paralelamente ao ensino na disciplina voltada aos projetos urbanos nos subúrbios - tornou-se possível uma reflexão mais profícua e um aprofundamento contínuo de conteúdos pedagógicos em sala de aula. Estes também se alimentam dos aportes dos produtos acadêmicos dos alunos que carregam informações repartidas coletivamente por aqueles colegas que vivenciam cotidianamente a área. $O$ trabalho de observação e a discussão conjunta, frequentes entre alunos cursando a disciplina juntos, e eventuais com agentes locais, tornaram-se premissas para o desenvolvimento dos projetos urbanos, possibilitando colocar os alunos como um todo em contato com problemáticas que estão presentes na cidade real.

A ênfase tem sido cada vez mais levar ao aluno a uma prática projetual que tenha um comprometimento com a sociedade. Neste sentido, a orientação ao trabalhar na região suburbana é de uma busca de valores presentes na identidade local e da região. As soluções arquitetônicas e urbanísticas mais recomendadas são aquelas que vão ao encontro de formas urbanas que se afastem de padrões homogeneizantes de ocupação do solo. A relevância dada são aos aspectos singulares identificados nas relações entre público e 
privado, modos de apropriação dos espaços coletivos e relação espaços livres e edificados suburbanos entrevistos nas investigações do tecido urbano e nas trocas com agentes locais.

\section{Os desafios metropolitanos contemporâneos nos produtos acadêmicos}

Na disciplina voltada ao projeto urbano, trabalhamos na porção suburbana ao longo dos eixos de transporte (trem, metrô e BRT) que fracionam drasticamente os tecidos urbanos desta macrorregião desde o início da integração dessas áreas à malha urbana. Nesta são privilegiados os distintos recortes nos quais identificamos por sua localização estratégica nos subúrbios a possibilidade de um compartilhamento de experiências por um maior número de alunos, seja esta relacionada à existência de subcentro de comércio e serviços, ou à fácil acessibilidade, ou mesmo de ambos.

Após visita técnica de reconhecimento, ampla discussão em sala de aula sobre a condição contemporânea e seu rebatimento na região, e desenho de seções urbanas que viabilizem a experiência em uma escala mais aproximada da área de projeto, estratégias projetuais preliminares são identificadas pelos alunos visando resolver problemas vistos menos como conflitos e mais como oportunidades. A cada semestre letivo e em função da mudança de área de projeto no interior dos subúrbios, são levantadas e priorizadas distintas ou similares questões para o projeto, embasadas por uma empatia com algum aspecto singular da área de projeto em muito facilitada pelo conhecimento prévio da área por parte de muitos alunos. De um modo geral, têm sido priorizados em todos os recortes estudados:

- O fracionamento do tecido urbano que divide o território em duas ou mais partes segregadas.

- A presença de terrenos subutilizados remanescentes de atividades logísticas e industriais, ou de espaços residuais, situados embaixo de viadutos que atravessam linhas férreas e a linha metroviária ou em decorrência da implantação do sistema BRT (Bus Rapid Traffic).

- O potencial para densificação residencial com uma tipologia que se contraponha a mais recente de condomínios exclusivos, excludente e provocadora de enclaves no tecido urbano.

- A perda de oportunidade no aproveitamento da proximidade de dinâmicas de escalas distintas - microlocal, local e metropolitana para dinamização urbana.

- A falta de interligação entre distintas modalidades de transporte prejudicando o conforto dos usuários.

- A demanda por equipamentos culturais e de lazer inexistentes.

No intuito de responder aos desafios metropolitanos elegemos inicialmente o bairro de Madureira como recorte a ser trabalhado nos subúrbios cariocas. Madureira é uma centralidade muito dinâmica, com um comércio intensíssimo que atrai grande número de pessoas que vivem nos subúrbios e nas periferias da Metrópole do Rio de Janeiro. Seu centro comercial se situa entre duas estações de trem das linhas do Ramal Deodoro 1 e do Ramal Belford Roxo (ver Figura 8) que distam entre si menos de 500 metros. Essas linhas férreas impulsionaram o crescimento local desde o início do século XX e ajudaram a fortalecer o comércio também intensificado com a instalação de um grande mercado em Madureira, em 1914.

Sem dúvida, essas linhas férreas se converteram ao longo do tempo em fortes barreiras na continuidade do tecido urbano. Além do que, com a sua presença provocaram o surgimento de outras infraestruturas pesadas no bairro - os viadutos voltados a conectar os três lados cortados pelas ferrovias. Recentemente, com a implantação do sistema de BRT (Bus Rapid Traffic) no Rio de Janeiro, outro viaduto exclusivo foi construído ao lado dos existentes. Outro aspecto significativo de Madureira, como dos demais subúrbios cariocas, é a convivência de formalidades e informalidades. Ao lado de manifestações tradicionais, como, por exemplo, as escolas de samba Portela e Império Serrano, existem novas expressões como o frenético "Baile Charme", um evento de concentração popular que acontece embaixo de um de seus viadutos.

$\mathrm{Na}$ sequência, o bairro suburbano de Vicente de Carvalho foi contemplado, com a motivação de ser atualmente um dos mais importantes locais de integração de modais de transporte na Zona Norte, portanto, já experimentado por muitos de nossos alunos. Em seu território ocorre hoje a intercessão de uma linha de metrô implantada sobre os trilhos da antiga linha férrea que servia à rede de abastecimento de água do Rio - o Ramal Rio d'Ouro - e a recém-criada linha de BRT (Bus Rapid Traffic), para a qual convergem inúmeras linhas de ônibus. A consequência desta intercessão é por um lado uma intensificação da dinâmica urbana, e por outro, um aumento da fragmentação do tecido urbano que favorece a segregação socioespacial já existente entre os dois lados da antiga linha férrea.

Cada vez mais uma das partes do bairro se valoriza e recebe inversões privadas e públicas, enquanto a outra se desvaloriza e amplifica a sua degradação. A parte valorizada corresponde aquela para a qual afluem as pessoas que buscam a interconexão das modalidades de transporte e o comércio que tende a 
especializar-se com o dinamismo urbano. A parte desvalorizada se situa no lado bordeado pelos morros em cujas encostas se encontra uma grande favela, residência dos estratos mais vulneráveis de sua população.

Para exemplificar e analisar as questões apresentadas, utilizamos produtos acadêmicos elaborados por equipes de alunos da disciplina em dois diferentes semestres letivos que adotaram premissas diferenciadas e chegaram a resultados variados, respectivamente, em Madureira e em Vicente de Carvalho. $O$ produto destacado como exemplo para o recorte de Madureira propõe-se a enfrentar simultaneamente dois desafios: minimização do efeito de fracionamento do tecido urbano causado pela linha férrea e aumento de qualidade ambiental e urbana no centro regional existente. A preocupação nesse enfrentamento foi de manter valores suburbanos e do bairro. Nesse sentido, a principal estratégia projetual busca ao mesmo tempo valorizar a presença do trem - marco do cotidiano dos subúrbios, através do aumento de sua visibilidade para os transeuntes e passageiros, e dar condições a permanência do intenso comércio de pequeno porte, traço próprio da vida comercial de Madureira, com a oferta de espaços apropriados e ordenados para sua instalação ao longo dos corredores de fluxo qualificados utilizado por um grande contingente de pessoas.

Assim, a principal proposta do projeto urbano é o espessamento dos muros que separam a linha férrea do Ramal Deodoro 1 no trecho mais próximo à estação de Madureira para uma apropriação privada e coletiva (ver Figura 5), sem implicar obras de grande envergadura. A espessura dos muros possibilita comportar pequenos ambientes em dois níveis - já que a altura mínima exigida para cobrir as catenárias dos trens no Rio de Janeiro é de 7,5 metros - e integrar o tecido adjacente em ambos os lados da linha férrea.

Figura 5 - Planta geral e seções transversais atuais (a) e (b) e seção transversal com intervenção (c)
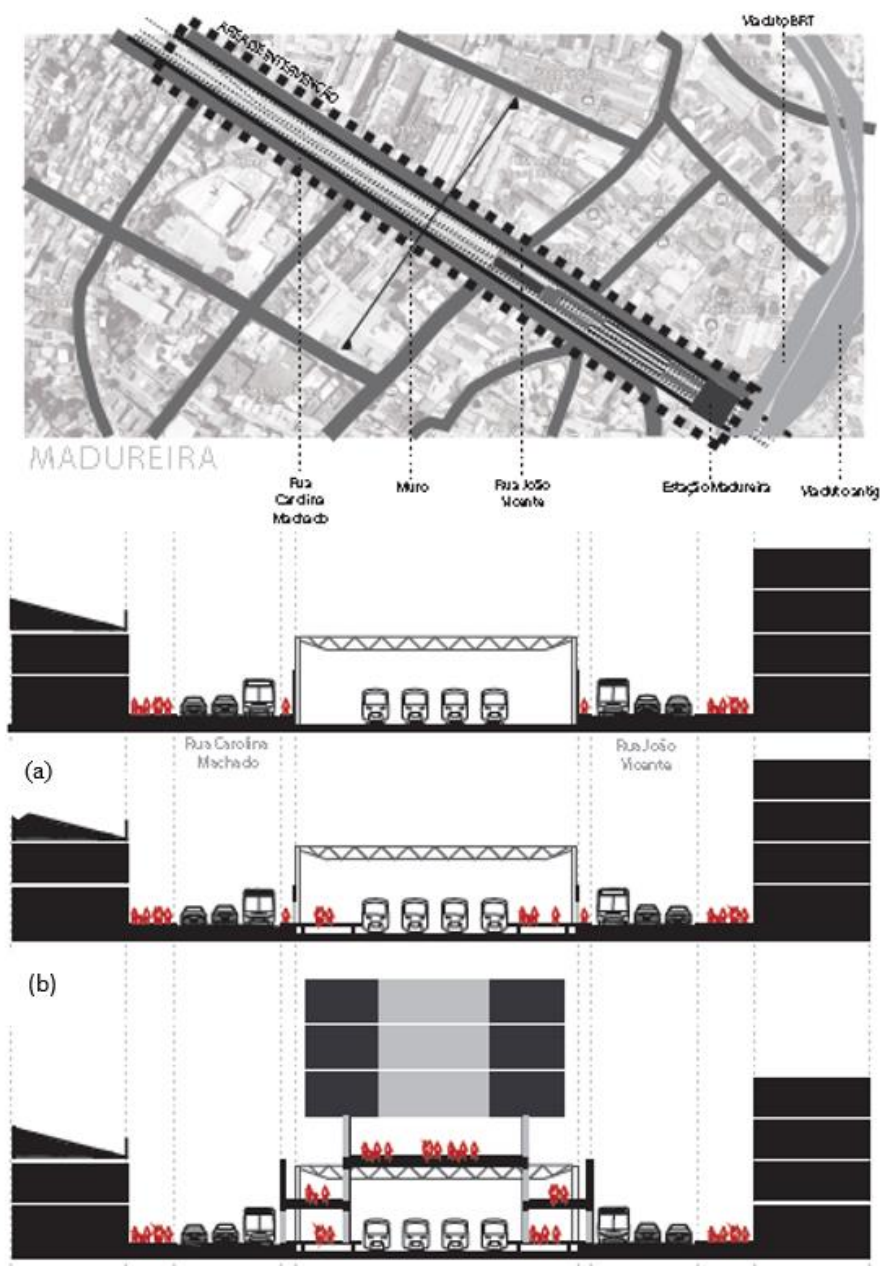

(c)

Autores: João Oliveira, Olivia Vigneron e Pablo Gestoso. Fonte: Acervo Atelier Integrado II - turma B. 
Os ambientes criados, voltados em parte para o logradouro público e em parte para a linha férrea, dão visibilidade ao trem e se prestam, por um lado, a prover um abrigo confortável nas paradas de ônibus e um passeio confortável para os transeuntes; e por outro, a uma ocupação ordenada pelo pequeno comércio local mantendo-o em localização estratégica junto à passagem destes, próxima às plataformas de embarque e desembarque do trem. Permitem também outras ocupações - institucional ou por oficinas e escritórios, sobretudo no nível superior, que se mostrem convenientes. Para isso, se subtrai a atual calçada ao longo dos muros nesse trecho, hoje subutilizada, por se tratar de espaço público inóspito. Complementa essa estratégia a recuperação da estação de trem que tem uma das mais significativas afluências de passageiros no Rio de Janeiro, e que se torna um edifício de três pisos sobre a plataforma praça, para uma ocupação por trabalho ou moradia.

Os três produtos acadêmicos apresentados a seguir foram realizados para o bairro de Vicente de Carvalho em dois semestres letivos de 2016. Apesar da preocupação comum com a integração do tecido fracionado pela linha metroviária, cada um deles utilizou estratégias projetuais bem distintas priorizando responder diferentes desafios metropolitanos apontados acima. Em um dos projetos a ênfase projetual volta-se para o adensamento em uma ampla área hoje subutilizada na qual há um galpão usado para o comércio de material de construção e um hipermercado, e um estacionamento. Pela proximidade à estação de metrô e da estação de BRT, é privilegiada em termos de acessibilidade e oportunidade para dinamização urbana.

As escolhas de projeto correspondem a uma compreensão das possibilidades oferecidas pela interação das dinâmicas das escalas metropolitana, urbana e local, coexistentes na área, que requerem alternativas variadas de ambientes espaciais para exercício de suas práticas. A experiência similar nos deslocamentos cotidianos e na utilização de ambiências de estação ferroviária por estudantes autores do projeto sem dúvida facilitou uma acurada observação dos processos de apropriação desse espaço.

Destaca-se na organização espacial do projeto a valorização dada às áreas livres públicas ao nível do solo - local de diferentes práticas no cotidiano suburbano, mas que devem ser suficientemente controladas por quem "habita" os edifícios, para garantir sua segurança e manutenção. Também há uma plataforma elevada de atravessamento da linha metroviária integrada a terminais de ônibus, com dimensão suficiente para comportar com conforto o fluxo de pedestres volumoso e o comércio ambulante (ver Figura 6).

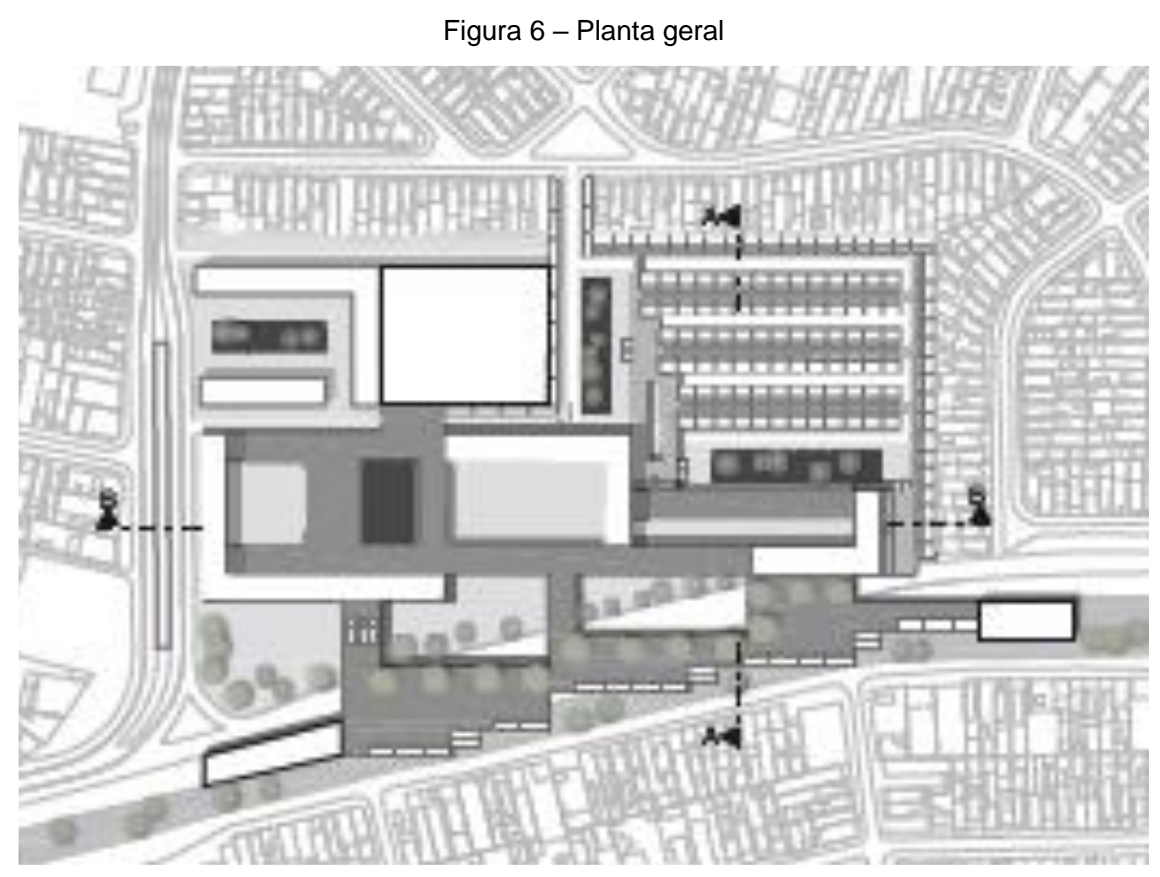

Autores: André Ricardo, Carolina Quintanilha, Gabriela Figueiredo e Roger Peicho. Fonte: Acervo Atelier Integrado II - turma B.

Por fim, sobressaem diferentes soluções para "habitar" nos edifícios, de acordo com proximidade ou afastamento dos equipamentos de transporte - estação metroviária, estação de BRT e terminais de ônibus e adjacência à trama urbana de grão pequeno. As soluções de "habitar" 1,2 e 3 correspondem em 
alternativas diferentes relacionadas a dimensionamento, a relação do íntimo e social, e a área livre e edificada, da escala metropolitana à local, à medida desta proximidade ou afastamento (ver Figura 7).

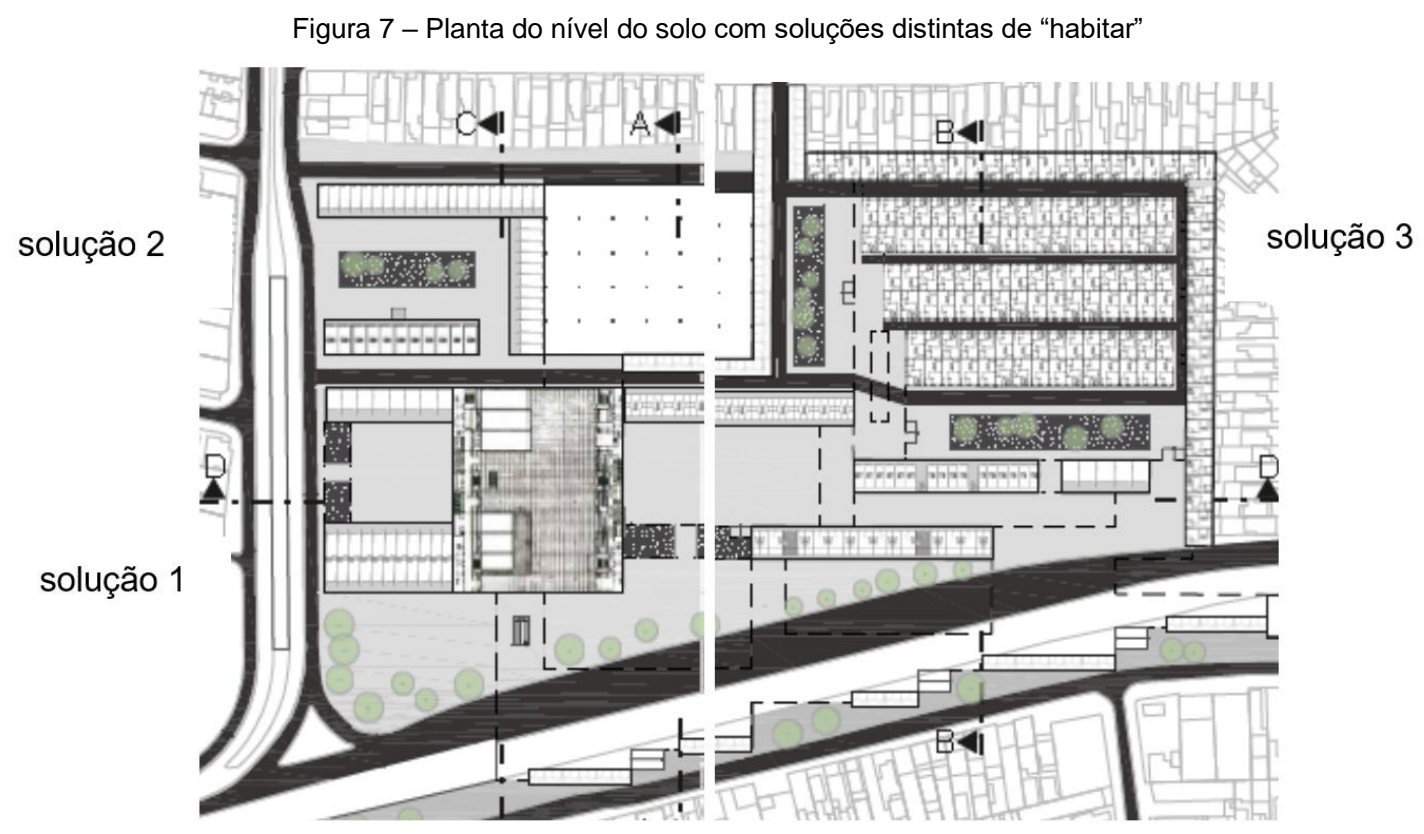

Autores: André Ricardo, Carolina Quintanilha, Gabriela Figueiredo e Roger Peicho. Fonte: Acervo Atelier Integrado II - turma B.

O projeto seguinte que enfoca a mesma ampla área subutilizada de Vicente de Carvalho se apoia no potencial de dinamismo nos subúrbios propiciado pela intensidade de atividades do âmbito do privado exercidas no espaço público, com ênfase na ampliação de áreas livres públicas de qualidade que atendam a demanda por equipamentos culturais e de lazer insuficientes.

Assim, é proposta tanto a criação de plataformas elevadas sobre a linha metroviária que se constituem uma continuidade das calçadas adjacentes, unindo o tecido urbano fracionado; quanto de uma grande esplanada integrada ao galpão existente. No primeiro caso, decorrem da implantação de edifícios "grampos" apoiados nos muros da faixa de domínio da linha de metrô, que também propiciam nos níveis superiores espaços para o "habitar". No segundo caso, é complementada por edificações uniformemente distribuídas com a função de "sentinelas", suporte para diferentes práticas. Como no projeto anterior, há uma compreensão da necessidade e da possibilidade de investir no controle pulverizado propiciado pela presença de atividades e usuários (ver Figura 8).

Figura 8 - Esquemas diagramáticos.
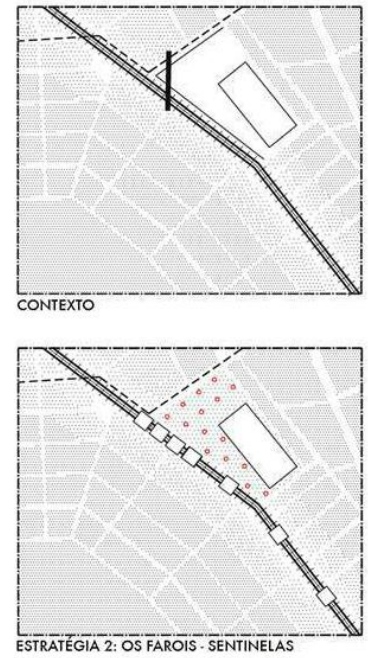
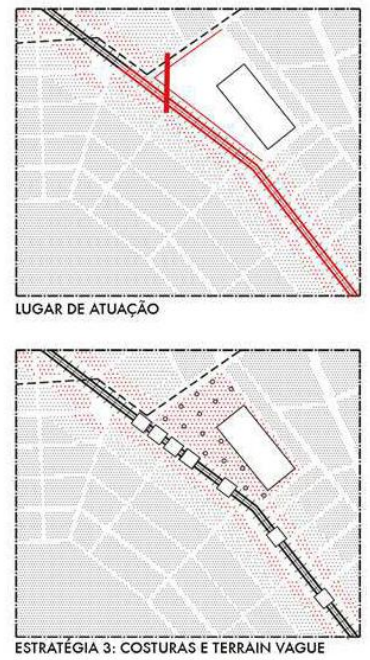
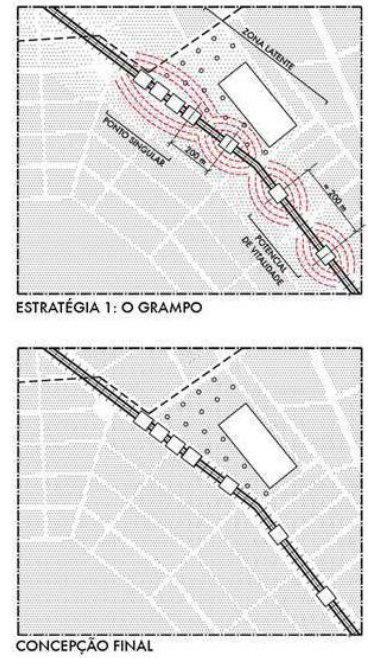

Autores: Carolina Hackme, Conrado Ely, Irantzu Berciano e Nina Andreatta. Fonte: Acervo Atelier Integrado II - turma B. 
Por fim, vale mencionar projeto que trouxe um importante aporte a partir da experiência pessoal dos seus integrantes, residentes da periferia metropolitana, na vivência em situações relacionadas à apropriação espacial com similaridades na área estudada. Do mesmo modo, sua relevância se dá pela correspondência a uma resposta sensível aos aspectos morfológicos e identitários identificados na pesquisa na escala microlocal em trechos dos subúrbios cariocas.

Como os demais, o projeto visa atenuar o fracionamento físico do tecido urbano decorrente da presença da linha de metrô. No entanto, já de início inova por ter uma preocupação também com as barreiras sociais, optando por atuar no lado oposto ao de maiores interesses do mercado, no qual a intervenção poderia significar um maior impacto social e urbano. A área escolhida para o projeto foi a parte adjacente ao Morro do Juramento, ocupado por um complexo de favelas totalizando cerca de 3.500 domicílios nos quais residem quase 12 mil pessoas (IBGE, 2010).

$\mathrm{Na}$ sequência, em uma contraposição crítica aos empreendimentos de grande porte, propõe diversas operações dependentes de menores e graduais inversões que pudessem acontecer ao longo do tempo, decorrentes de investimentos por parte de pequenos empresários, proprietários e mesmo moradores. Esta forma de produção urbana é de fato a que vem ocorrendo historicamente na realidade suburbana.

Para isso, o projeto busca equipar o espaço com tipomorfologias pré-existentes, correspondente ao estilo de vida e agentes do espaço suburbano através de meticuloso levantamento e análise do formato e dimensionamento de quadras e lotes e da implantação dos edifícios nos lotes. Daí resultou propostas de edifícios na escala do habitar "pequeno" ou "muito pequeno", e também ajustado à apropriação coletiva, da escala do habitar "médio", no qual interage um número maior de pessoas. Em confronto com empreendimentos de grande porte que preveem privatização dos espaços coletivos, os edifícios propostos valorizam ruas como espaço de convivência, mesmo que privativas, como próprio dos subúrbios (ver Figura 9). Esta iniciativa amplifica a difusão do controle do espaço público.

Figura 9 - Planta geral, diagrama, plantas e perspectivas das situações tipo.

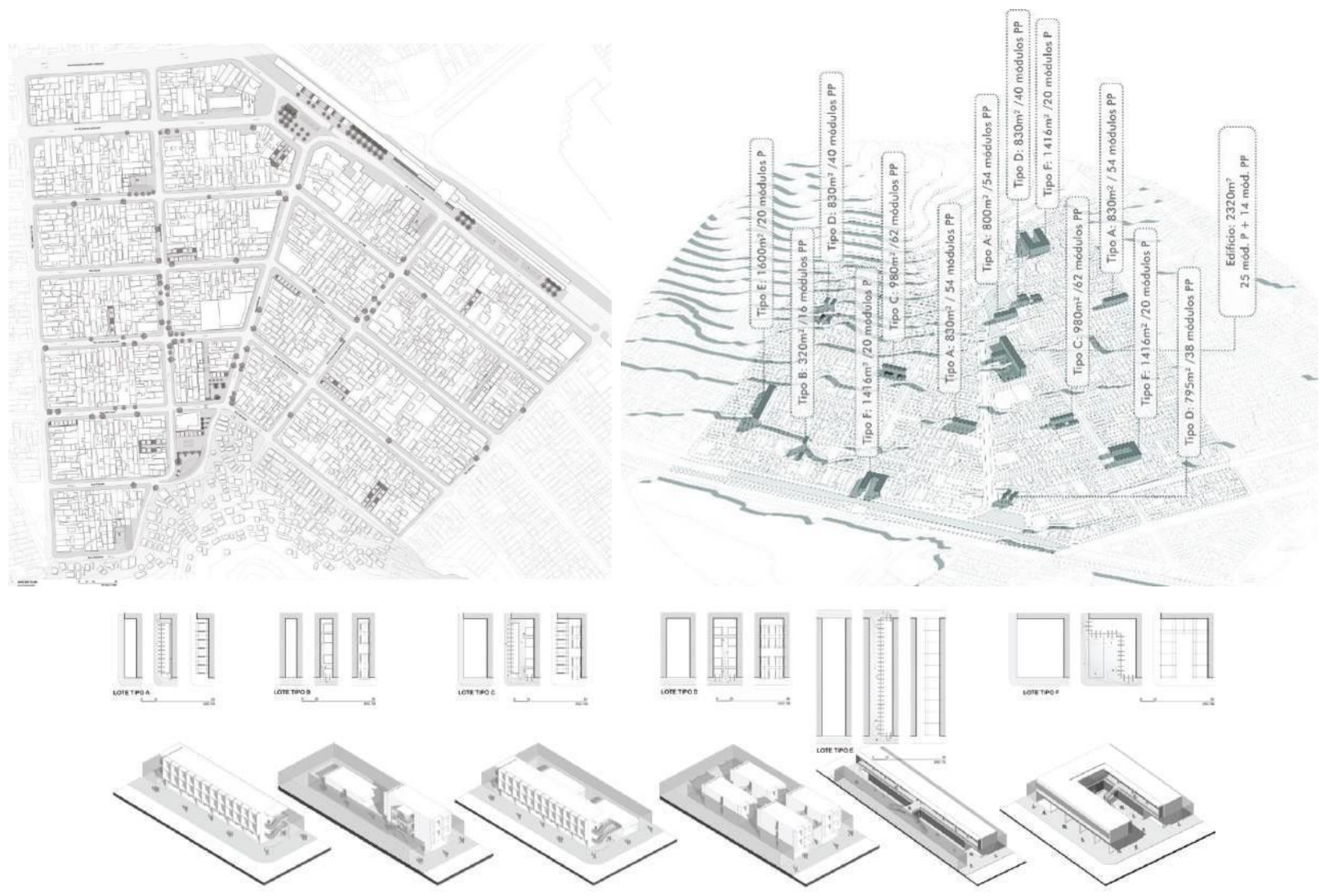

Autores: Isabelle Amorim, Leonardo Mesquita, Lorena Ohana e Natalia Santos. Fonte: Acervo Atelier Integrado II - turma B. 


\section{COMENTÁRIOS CONCLUSIVOS}

\section{Ensino, pesquisa e extensão nos subúrbios cariocas: insumo para o projeto}

Com os progressivos resultados dos produtos acadêmicos e das investigações e extensão correlatas que vêm se desenvolvendo paralelamente, vão sendo feitos constantes ajustes e delineadas premissas que hoje são adotadas no ensino do projeto urbano na turma B da disciplina Ateliê Integrado II. No âmbito do projeto pedagógico, o trabalho de observação, análise e discussão coletiva cada vez mais vem ganhando espaço na sala de aula. As trocas entre alunos do mesmo período ou de períodos precedentes incluíram-se obrigatoriamente na pauta. Do mesmo modo, as visões dos agentes locais inserem-se necessariamente a cada semestre através de apresentações e outras atividades programadas.

Em termos de conteúdo programático, as temáticas enfatizadas são cada vez mais voltadas a processos e soluções que apresentem modos de resistência inovadores mesmo que calcados nas pré-existências a padrões genéricos e homogeneizantes. Nelas é possível vislumbrar alternativas para agentes imobiliários ligados ao médio ou pequeno capital e à própria rentabilização dos habitantes. Neste sentido, aliás, verificase um total rebatimento com iniciativas recorrentes nos tecidos suburbanos.

Nos processos de produção das formas suburbanas e em sua apropriação se destacam como característicos, justamente algumas das operações que vêm sendo cada vez mais incorporadas nos produtos acadêmicos: o aumento do número de domicílios em um terreno que antes abrigava menos; o compartilhamento de atividades de trabalho e moradia em um mesmo imóvel; a reversão de critérios do social e do íntimo nos espaços público e privado; a diversidade de tipologias em um pequeno recorte urbano. Nestes processos estão presentes as ações dos pequenos agentes, ou seja, proprietários de terrenos e de edifícios, empresários de poucos aportes e mesmo moradores.

Da atuação minimalista desses agentes se verifica uma morfologia urbana e tipologia edilícia que favorece uma diversidade nas dimensões dos lotes e uma variedade tipológica que significa uma oferta maior de escolhas e a produção de formas menos ou mais valorizadas de moradia. Neste sentido, representa uma saudável diversidade funcional e social, fonte de convivência da diferença. Para alguns dos seus atuais moradores corresponde também à possibilidade de permanência. Assim, se mantêm beneficiados 0 estreitamento dos laços de identidade, as redes de sociabilidade e a convivência humana.

\section{Uma agenda pedagógica e conceitual para o ensino do projeto urbano}

A condição metropolitana contemporânea traz desafios para o ensino da arquitetura e urbanismo, exigindo assim em se desenvolver uma agenda conceitual e pedagógica que consiga responder coerentemente à realidade. É importante permitir formar um profissional que tenha uma atitude crítica relacionada aos processos urbanos, além de possuir um saber técnico que viabilize sua atuação com responsabilidade social e ambiental. Este profissional deve ser também capaz de se opor à lógica de pensamento esquemático e fragmentado, buscando a justaposição de múltiplos pontos de vista e formas de planejamento.

Neste sentido interessam destacar aspectos compartilhados com os autores mencionados no início do artigo, referências para a consolidação de nossa agenda conceitual e pedagógica. Importa introduzir uma visão do processo, que inclua outros agentes produtores do espaço, e um entendimento da cidade e seu território que se rebata no cotidiano e se construa no interior do tecido urbano, conseguindo se aproximar das pessoas e seus desejos. Deve-se considerar uma forma de ação acerca da cidade que se opõe à verificada nos planos urbanísticos e em sua escala de amplitude que resultam metodologicamente em amplos diagnósticos, e na execução de operações destituídas de materialidade.

Há ainda a enfatizar a necessidade do combate à segregação socioespacial; a prevalência à qualidade do habitar entendida possível a partir da conformação de bons ambientes urbanos; e o respeito às preexistências tendo em conta a ininterrupta dinâmica urbana. Em termos pedagógicos se complementa com a perspectiva de atendimento ao cotidiano, ao comum e ao específico, conforme indicações do Professor Bernardo Secchi (2006). Este pensamento está em consonância com demandas de valorização do espaço da coletividade na cidade e com alternativas para a transformação do espaço privado com o reconhecimento das especificidades das práticas sociais que se desenvolvem nos lugares. 


\section{REFERÊNCIAS}

ABREU, Maurício de A. Evolução urbana do Rio de Janeiro. 4. ed. Rio de Janeiro: IPP, 2006. [1987]

BUDETT, Ricky; RODE, Philipp (orgs.) The endless city. London \& New York: Phaidon Press, 2007.

CÂMARA METROPOLITANA DE INTEGRAÇÃO GOVERNAMENTAL. Caderno metropolitano 1: a retomada do planejamento. Rio de Janeiro, novembro de 2015. http://www.camarametropolitana.rj.gov.br/cadernos/CADERNO1.pdf. Acesso em setembro de 2018 .

PETRAGLIA, Carmen Lúcia; LEITE, Vera França e (coords.). Caderno metropolitano 2: centralidades: territórios de perspectivas para políticas públicas. Rio de Janeiro: Câmara Metropolitana de Integração Governamental, 2017. http://www.camarametropolitana.rj.gov.br/cadernos/CADERNO2.pdf. Acesso em setembro de 2018.

SANTOS, Milton. A urbanização brasileira. São Paulo: Hucitec, 1993.

SECCHI, Bernardo. Primeira lição de urbanismo. São Paulo: Perspectiva, 2006. (2000, edição italizana)

TSIOMIS, Yannis. "Projeto Urbano, Embelezamento e Reconquista da Cidade". In: PINHEIRO MACHADO, Denise B.; VASCONCELLOS, Eduardo Mendes. Cidade Imaginação. Rio de Janeiro; UFRJ/PROURB, 1996. Pp.24-29.

NOTA DO EDITOR (*) O conteúdo do artigo e as imagens nele publicadas são de responsabilidade do(s) autor(es). 